\title{
MEMBRANAS DE POLIURETANO NA GEOMETRIA FIRBAS OCAS PARA REMOÇÃO DE COMPOSTOS SULFUROSOS DA NAFTA POR PERVAPORAÇÃO
}

\author{
R. A. AMARAL ${ }^{1}$, C. P. BORGES ${ }^{1}$ e A. C. HABERT ${ }^{1}$ \\ ${ }^{1}$ Universidade Federal do Rio de Janeiro, Instituto Alberto Luiz Coimbra de Pós-Graduação e \\ Pesquisa de Engenharia, Programa de Engenharia Química \\ E-mail para contato: ramaral@ peq.coppe.ufrj.br
}

\begin{abstract}
RESUMO - A remoção de enxofre em combustíveis utilizando processos de separação com membranas (PSM), em particular o processo da pervaporação (PV) tem sido objeto de estudo em um crescente número de artigos e as vantagens incluem seletividade, baixo custo e simplicidade de operação. Nesta pesquisa membranas de poliuretano (PU) foram preparadas na geometria plana e fibras ocas e seu desempenho foi avaliado no processo de dessulfurização por PV. Como carga líquida foi escolhida uma mistura binária contendo $1500 \mathrm{mg} . \mathrm{Kg}^{-1}$ de 2-metil-tiofeno em iso-octano e os resultados de PV tem mostrado um alto desempenho da membrana na separação do composto de enxofre, sendo o principal destaque da pesquisa.
\end{abstract}

\section{INTRODUÇÃO}

O petróleo apresenta uma composição complexa, sendo constituído basicamente de hidrocarbonetos com diferentes pontos de ebulição. O tipo predominante de hidrocarboneto pode ser utilizado como critério de classificação do petróleo, o qual pode ser parafínico, naftênico, aromático ou misto. Após o processamento do óleo bruto em refinarias, são obtidos vários derivados com inúmeras aplicações. Dentre as impurezas do petróleo, podem-se destacar os compostos sulfurosos, nitrogenados, oxigenados e organometálicos, além de água, sais minerais e outros sedimentos como areia. A presença de compostos sulfurosos contribui para a corrosão de dutos e equipamentos, desde sua extração até a refinaria, como também na poluição atmosférica, liberado, principalmente como dióxido de enxofre $\left(\mathrm{SO}_{2}\right)$, na combustão da gasolina, diesel e querosene. $\mathrm{O} \mathrm{SO}_{2}$ em combinação com o oxigênio atmosférico e a água na forma vapor provoca o fenômeno conhecido como "chuva ácida". A água da chuva, contendo ácido sulfúrico $\left(\mathrm{H}_{2} \mathrm{SO}_{4}\right)$ ao atingir a superfície terrestre, contamina os solos e as águas, provocando modificações na sua composição. Estas transformações afetam as cadeias alimentares, destroem vegetações e corroem estruturas metálicas de prédios e construções civis. Concentrações elevadas de compostos sulfurosos no ar atmosférico também podem causar problemas respiratórios e irritações nas mucosas e pele de seres humanos. Em virtude dos crescentes problemas ambientais, a implementação de regulamentações mais rígidas, maior fiscalização e atuação dos órgãos reguladores estão sendo adotadas.

No Brasil, cerca de $70 \%$ do pool de gasolina é constituído por nafta oriunda do processo de craqueamento fluido catalítico (FCC, Fluid Catalytic Cracking, em inglês). De modo geral, nesta 


\section{9 a 22 de outubro de 2014 \\ Florianópolis/SC}

corrente pode ser encontrado um alto teor de enxofre (em média, 1.000 mg.kg-1, dependendo do petróleo e das condições que a originou), o que contribui diretamente para emissão de $\mathrm{SO}_{2}$ e corrosão de equipamentos e tubulações (Petrobras, 2003).

Diante deste cenário se torna necessário uma adequação tecnológica nos processos envolvidos na produção de combustíveis no Brasil a fim de alcançar os valores determinados ou recomendados pela legislação. Para atender as novas especificações estabelecidas pelo Conselho Nacional do Meio Ambiente (CONAMA) para os combustíveis, a Petrobras iniciou um intensivo programa de investimentos com unidades de tratamento para reduzir o teor de enxofre nos combustíveis. Neste ano de 2014, a Petrobras já disponibilizou em todo o território nacional as novas gasolinas "Comum" e "Premium" de ultrabaixo teor de enxofre (UBTE), apresentando teor máximo de enxofre de 50 mg. $\mathrm{kg}^{-1}$. Este índice representou uma redução de $94 \%$ em relação ao teor de enxofre das gasolinas anteriormente comercializadas $\left(800 \mathrm{mg} \cdot \mathrm{kg}^{-1}\right)$. Esta redução foi possível após uma modernização nas refinarias, utilizando a tecnologia de hidrodessulfurização (HDS). O investimento bilionário permitiu à Petrobras especificar os combustíveis, dentro do padrão europeu e norte-americano. (Petrobras, 2014)

A HDS é uma tecnologia que consiste na quebra da ligação química carbono-enxofre dos compostos sulfurosos pelo hidrogênio, gerando sulfeto de hidrogênio $\left(\mathrm{H}_{2} \mathrm{~S}\right)$ e hidrocarbonetos e apresenta desempenho acima de $99 \%$ na remoção de enxofre, mas é acompanhado pela hidrogenação de olefinas, resultando em perdas de octanagem. Além disso, o processo requer grandes investimentos de instalação e operacionais (consumo de hidrogênio, catalisador e energia). Dados de processo mostram que para reduzir o conteúdo de enxofre de $1.000 \mathrm{mg} . \mathrm{L}^{-1}$ para $100 \mathrm{mg} . \mathrm{L}^{-1}$, ocorre uma redução de $18 \%$ no conteúdo de olefinas e de $6 \%$ na octanagem na nafta, utilizando o processo de HDS (Song, 2003). Outros índices de redução são apresentados na Figura 1.
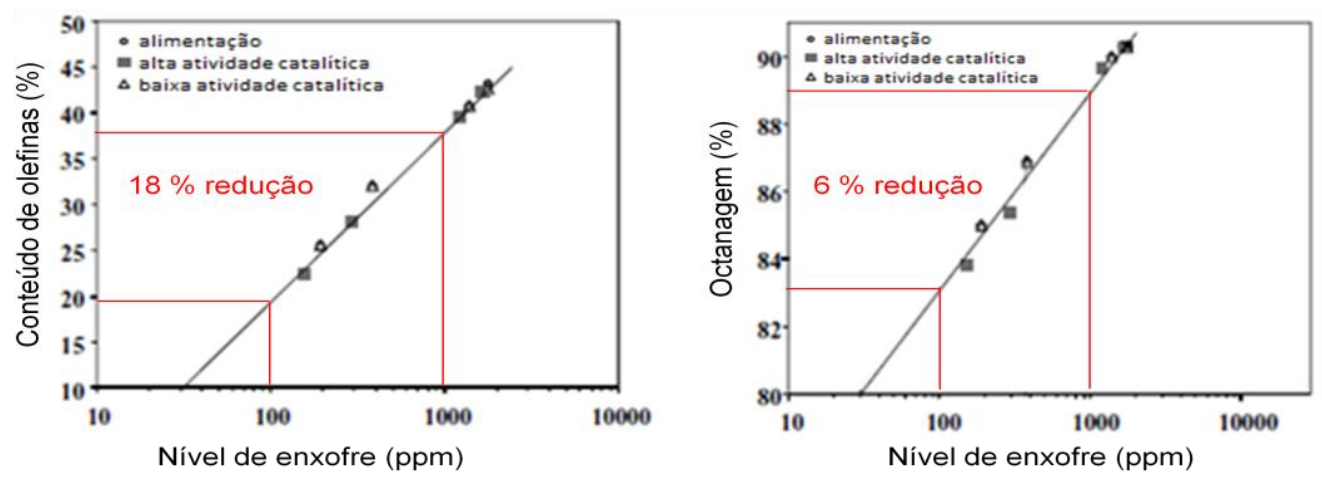

Figura 1- Relação entre a perda da octanagem e conteúdo de olefinas na redução do nível de enxofre da nafta por hidrodessulfurização. Adaptado de Song (2003).

Como alternativa ao processo convencional, membranas poliméricas têm sido utilizadas para promover a dessulfurização de correntes líquidas de hidrocarbonetos e a pervaporação (PV) tem sido o principal processo empregado (Liu et al., 2014; Yang et al,. 2013; Sha et al., 2012; Cao et al., 2011). No processo da PV, uma mistura líquida em contato com uma das superfícies da membrana, se difunde através da mesma, passando ao estado vapor no outro lado. 


\section{9 a 22 de outubro de 2014 \\ Florianópolis/SC}

A eficiência do processo de PV para dessulfurização está relacionada à utilização de membranas com afinidade aos compostos sulfurosos. As vantagens deste processo são normalmente características comuns dos Processos de Separação com Membranas (PSM), i.e., seletividade, baixo custo e simplicidade de operação, equipamentos compactos e modulares e facilidade para o aumento de escala. Quando comparado ao processo convencional de HDS de correntes líquidas de hidrocarbonetos, a PV possibilita a remoção de compostos organosulfurados em condições brandas de pressão e temperatura e dispensa o uso de hidrogênio e catalisadores, tornando o processo mais seguro e com menores custos operacionais (Liu et al., 2014).

A partir da revisão bibliográfica, foi verificado que a dessulfurização de correntes líquidas de hidrocarbonetos por PV, tem abordado desde o preparo de membranas com materiais que apresentem maiores seletividade e permeabilidade aos compostos sulfurosos e as influências das variáveis de processo, como temperatura, pressão de permeado, concentração dos componentes da alimentação e vazão de alimentação. Destas investigações, o uso de membranas na geometria plana tem sido amplamente empregado. Membranas na geometria de fibras ocas são auto-suportadas e desponta como a mais interessante do ponto de vista operacional e, portanto de aplicação em sistemas industriais por serem acomodadas em dispositivos modulares e que fornecerem uma alta relação de área de membranas por volume de módulo.

Diante deste contexto, o objetivo principal deste trabalho é obter membranas na geometria fibras ocas e avaliar o seu desempenho na dessulfurização de correntes líquidas de hidrocarbonetos pelo processo da pervaporação. Para o preparo das fibras, foi selecionado como polímero base o poliuretano (PU). O PU é uma classe de polímeros com uma grande variedade de grupos funcionais, permitindo a flexibilidade de combinar transporte desejável, propriedades térmica, química e mecânica.

\section{MATERIAIS E MÉTODOS}

Membranas poliméricas foram preparadas na geometria plana e fibras ocas para avaliar o desempenho do processo de dessulfurização através da dessulfurização. Para o preparo das membranas foi utilizado como polímero base o PU fornecido pela Basf, com o nome comercial Elastollan ${ }^{\circledR}$ PU1185A10 (base éter) na forma de grânulos. A membrana plana foi preparada a partir de uma solução contendo tetrahidrofurano (THF) (Tedia, com grau de pureza mínimo de 99) e $10 \%$ $(\mathrm{m} / \mathrm{m})$ de PU. Em seguida, parte da solução era vertida em placa de petri e colocada em uma capela com exaustão forçada para promover a formação da membrana polimérica com a evaporação completa do solvente. Para o preparo de membranas de fibras ocas, grânulos de PU foram fundidos em uma extrusora térmica ( $L A B-16 / 40, A X$ Plásticos) e para promover a geometria oca da fibra foi adaptada na saída da extrusora térmica uma matriz contendo dois orifícios concêntricos sendo que no orifício principal (agulha) era pressurizado óleo mineral e no espaço anular escoava o polímero fundido. Por fim, o fluido fundido sofria uma precipitação instantânea ao cair em um tanque contendo água microfiltrada a $25^{\circ} \mathrm{C}$ e a fibra formada era recolhida através de uma bobina com um motor adaptado, conforme representado na Figura 2. A bobina motorizada também promovia um tensionamento para as fibras ocas. A velocidade de recolhimento da fibra foi ajustada em 8 metros. $\min ^{-1}$. 


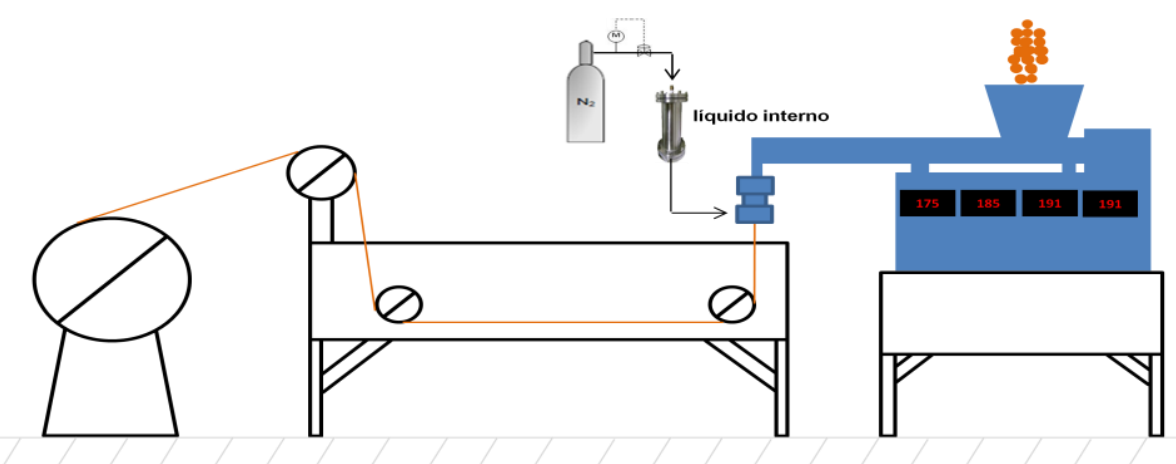

Figura 2 - Sistema de preparo de fibras ocas por extrusão térmica.

Por fim, ensaios de pervaporação foram realizados com as membranas planas e fibras ocas para avaliar o desempenho do processo de dessulfurização de uma mistura binária contendo 1.500 mg. $\mathrm{Kg}^{-1}$ de 2-metil-tiofeno em iso-octano. A solução contendo a mistura binária foi acondicionada em balão de vidro com temperatura controlada por uma placa de aquecimento. Para o caso das membranas produzidas na geometria plana, a amostra foi acondicionada e hermeticamente fechada em uma célula de permeação de aço inoxidável contendo uma entrada para a alimentação do líquido e duas saídas, uma para o concentrado e outra para o permeado. O lado superior da membrana ficava posicionado para a entrada da alimentação e a saída do concentrado e o lado inferior da membrana ficava posicionado para a saída do permeado. A linha do concentrado retornava para o mesmo balão de vidro através de uma bomba de engrenagens (Gear Pump Drive, Cole Parmer) adaptada em linha. Uma bomba de vácuo (E2M 0.7, Edwards), responsável por promover a diferença de pressão de vapor entre a alimentação e o permeado, foi conectada a uma grade de vidro com a função de coletar o vapor de permeado através de cristalizadores imersos em nitrogênio líquido a $196^{\circ} \mathrm{C}$ negativos. A pressão da bomba de vácuo no lado do permeado foi medida por meio de um sensor Pirani (APG100, Edwards). A coleta do permeado era realizada no estado estacionário, e o líquido coletado nos cristalizadores, correspondente ao permeado, foi pesado para determinação do fluxo de permeado. Para os testes com as fibras ocas, um feixe de fibras foi colado em uma conexão plástica e as fibras foram acondicionadas diretamente no balão de vidro de modo que a área externa das fibras ficasse em contato com o líquido da alimentação e o lúmen das fibras ficasse conectado com a saída do permeado. Para a determinação da composição do permeado, a amostra era analisada em um cromatógrafo a gás (CLARUS 500, Perkin Elmer), usando uma coluna capilar de sílica (Equity 1701, Supelco) e um detector por ionização de chama (FID, em inglês). A injeção das amostras no equipamento era feita por intermédio de uma seringa com escala em microlitros.

\section{RESULTADOS E DISCUSSÃO}

A Figura 3 apresenta os resultados de caracterização por microscopia eletrônica de varredura (MEV) das membranas confeccionadas na geometria plana e fibra oca. Para as duas membranas não se observou presença de defeitos e apresentaram uma seção transversal totalmente densificada. 


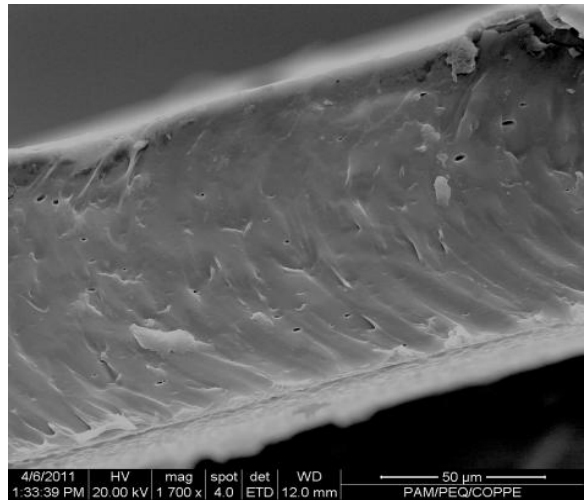

(a)

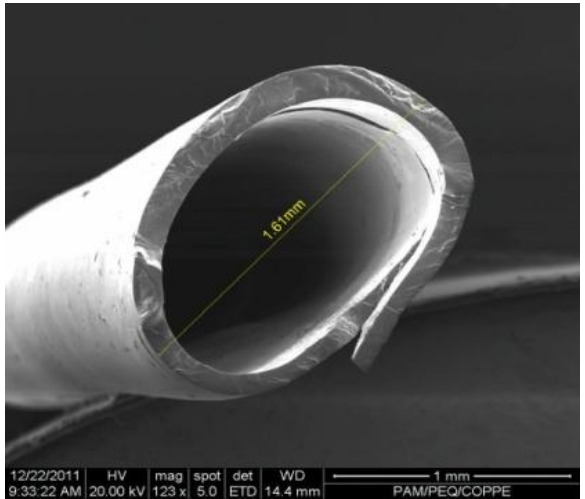

(b)

Figura 3 - Fotomicrografia das membranas na (a) geometria plana e (b) fibra oca.

Ensaios de pervaporação foram realizados para as membranas de fibras ocas e planas e a Figura 4 apresenta os resultados de variação do fluxo de permeado com a temperatura.

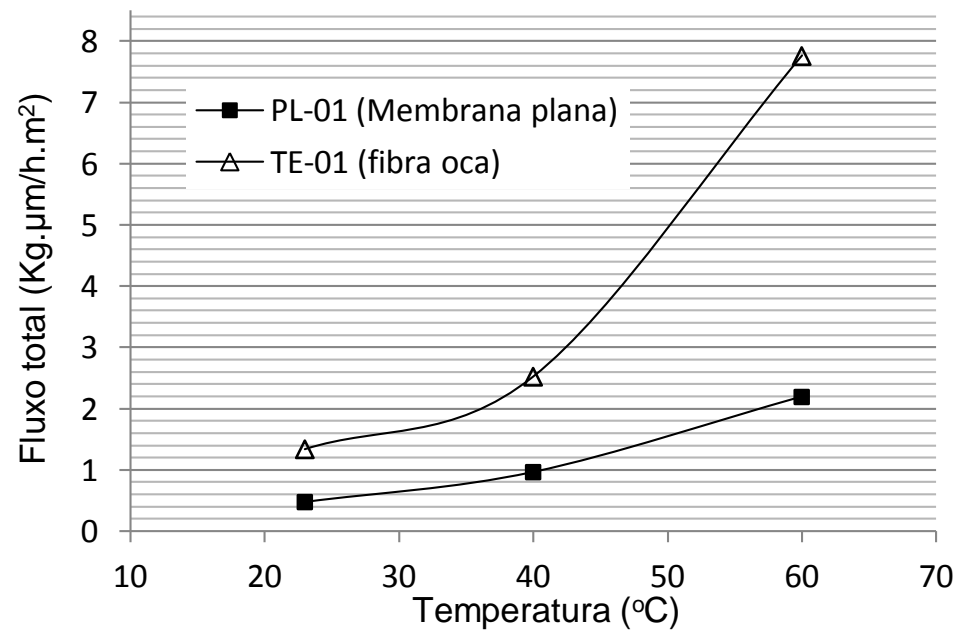

Figura 4 - Efeito da variação do fluxo de permeado com a temperatura para as membranas produzidas na forma plana e fibra oca.

O que pode ser observado na Figura 4 é que com o aumento da temperatura da carga líquida houve um aumento no fluxo de permeado, como esperado. A estrutura polimérica do PU combina domínios amorfos e cristalinos que aumentam o caminho de difusão e reduzem a mobilidade das cadeias da fase amorfa. Essa mobilidade é aumentada com o acréscimo de energia, aumentando a difusão nas cadeias poliméricas, que por consequência causa um aumento do fluxo de permeado. Com relação à comparação de fluxo entre as membranas, as fibras ocas apresentaram um maior desempenho no processo de dessulfurização por PV. Considerando que os materiais foram produzidos com o mesmo polímero base, que as membranas apresentaram uma morfologia isotrópica densa e que o fluxo foi normalizado pela espessura de cada membrana correspondente, esperava-se 
que os resultados ficassem bastante próximos. Uma das hipóteses para explicar o melhor desempenho das fibras ocas foi a possibilidade de defeito em alguma fibra oca utilizada para a confecção do módulo. Para corroborar com a hipótese, as membranas foram comparadas quanto ao fator de enriquecimento, conforme apresentado na Figura 5. O fator de enriquecimento é uma medida da capacidade de separação, sendo definido pela relação entre a composição do componente mais permeável no permeado e a composição do mesmo componente na alimentação.

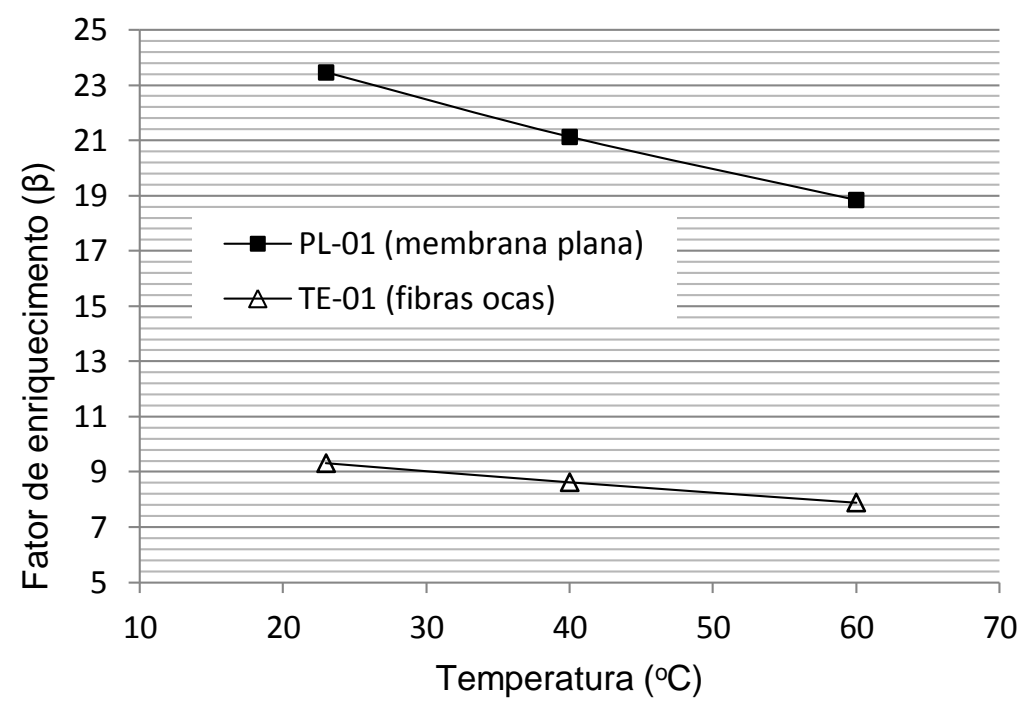

Figura 5 - Efeito da variação do fator de enriquecimento com a temperatura para as membranas produzidas na forma plana e fibra oca.

Conforme hipótese aventada, o módulo de fibras ocas provavelmente apresentou um ou mais fibras com defeitos, e isto explica a queda significativa no fator de enriquecimento, apresentado na Figura 5 e o maior fluxo de permeado, apresentado na Figura 4 quando comparado à membrana plana. Os resultados apresentados na Figura 5 também mostram que a corrente de permeado foi enriquecida com o composto sulfuroso mais de 7 vezes para as fibras ocas e 18 vezes para a membrana plana.

\section{CONCLUSÕES}

Membranas poliméricas de poliuretano foram produzidas na geometria plana e fibras ocas e tiveram seu desempenho comparado no processo de dessulfurização por pervaporação de uma mistura binária contendo 2-metil-tiofeno como contaminante sulfuroso. Os resultados mostraram um aumento no desempenho de processo com o aumento da temperatura para as duas geometrias de membranas. A hipótese de defeito no módulo de fibras ocas foi aventada, uma vez que apresentou fluxo de permeado superior à geometria plana e uma queda significativa no fator de enriquecimento. Os resultados mostraram que a corrente de permeado foi enriquecida com o composto sulfuroso mais de 7 vezes, no caso das fibras ocas e para a membrana plana teve a capacidade de separação superior 
a 18 vezes, mostrando um alto desempenho da membrana de poliuretano no processo de dessulfurização.

\section{REFERÊNCIAS}

LIU, K., FANG, C-J., LI, Z-Q., YOUNG, M., 2014, "Separation of Thiophene/n-heptane Mixtures using PEBAX/PVDF-composited Membranes via Pervaporation”, Journal of Membrane Science, v. 451, p.p. 24-31.

CAO, R., ZHANG, X., WU, H., WANG, J., LIU, X., JIANG, Z., 2011 “ Enhanced pervaporative desulfurization by polydimethylsiloxane membranes embedded with silver/silica core-shell microspheres", Journal of Hazards Matererials, v 187, p.p 324-332.

PETROBRAS, "Impacto das futuras especificações na formulação da gasolina brasileira", 2003. Disponível em: 〈http://www2.petrobras.com.br>. Acesso em 15 jan. 2011, 19:00.

PETROBRAS, "Conheça os benefícios das novas gasolinas S-50”, 2003. Disponível em: <http:// http://www.petrobras.com.br/fatos-e-dados/conheca-os-beneficios-das-novas-gasolinas-s50.htm>. Acesso em 26 abr.2014, 21:00.

SONG, C., 2003, "An Overview of New Approaches to Deep Desulfurization for Ultra-clean Gasoline, Diesel Fuel and Jet Fuel", Catalysis Today, v. 86, p.p. 211-263.

YANG, Z-J., WANG, Z-Q., LI, J., CHEN, J-X., 2013, "Enhancing FCC Gasoline Dessulfurization Performance in a Polyphosphazene Pervaporative Membrane", Separation and Purification Technology, v. 109, p.p 48-54.

Sha, S., Kong, Y., Yang, J., 2012 "Effect of charge-transfer complex between gasoline components $/ \mathrm{C}_{60}$ on desulphurization properties of $\mathrm{C}_{60}$-filled ethyl cellulose hybrid membranes”, Journal of Membrane Science, v. 415-416, p.p 835-841. 